DOI: https://doi.org/10.15688/jvolsu4.2017.6.7

UDC 94(47)083

Submitted: 03.05.2017

LBC 63.3.2(53)

Accepted: 19.10 .2017

\title{
RUSSIAN GENERALS IMPRISONED IN THE PETER AND PAUL FORTRESS IN 1917
}

\author{
Nikolay R. Slavnitskiy \\ State Museum of the History of St. Petersburg, Saint Petersburg, Russian Federation
}

\begin{abstract}
In the article, on the basis of documentary archival materials, the fate of the Russian generals who were imprisoned in the Peter and Paul Fortress (in St. Petersburg) in 1917 is studied. During the revolutionary events (in the spring, after the February Revolution, and in the autumn, after the October Revolution) many people, including the military, were imprisoned. The prison of the Trubetskoy bastion in the Peter and Paul Fortress was one of the main political prisons, therefore some generals were sent there. In March, former military ministers, the district commander, as well as those who were associated with the imperial family were imprisoned. In Summer, one of the participants in the speech of L.G. Kornilov, as well as some monarchists were also imprisoned. The third wave took place in the autumn, when the military ministers of the Provisional Government, the command of the Northern Front and other generals opposed to the Soviet power were detained. In total, in 1917, 15 or 16 generals were in prison fortresses, and they were people of different convictions. Some of them during the civil war found themselves on the side of the Reds, some on the White side, some of them emigrated. Therefore, let us state that the imprisonment in the fortress did not affect their further choice. The study of the documentary materials of the commandant's office of the Peter and Paul Fortress made it possible to identify the names of those who were imprisoned in it, as well as to find out some details of their conclusion.

Key words: February Revolution, October Revolution, Peter and Paul Fortress, political repressions, Trubetskoy Bastion prison, Civil War.

Citation. Slavnitskiy N.R. Russian Generals Imprisoned in the Peter and Paul Fortress in 1917. Vestnik Volgogradskogo gosudarstvennogo universiteta. Serija 4, Istorija. Regionovedenie. Mezhdunarodnye otnoshenija [Science Journal of Volgograd State University. History. Area Studies. International Relations], 2017, vol. 22, no. 6, pp. 69-76. (in Russian). DOI: https://doi.org/10.15688/jvolsu4.2017.6.7
\end{abstract}

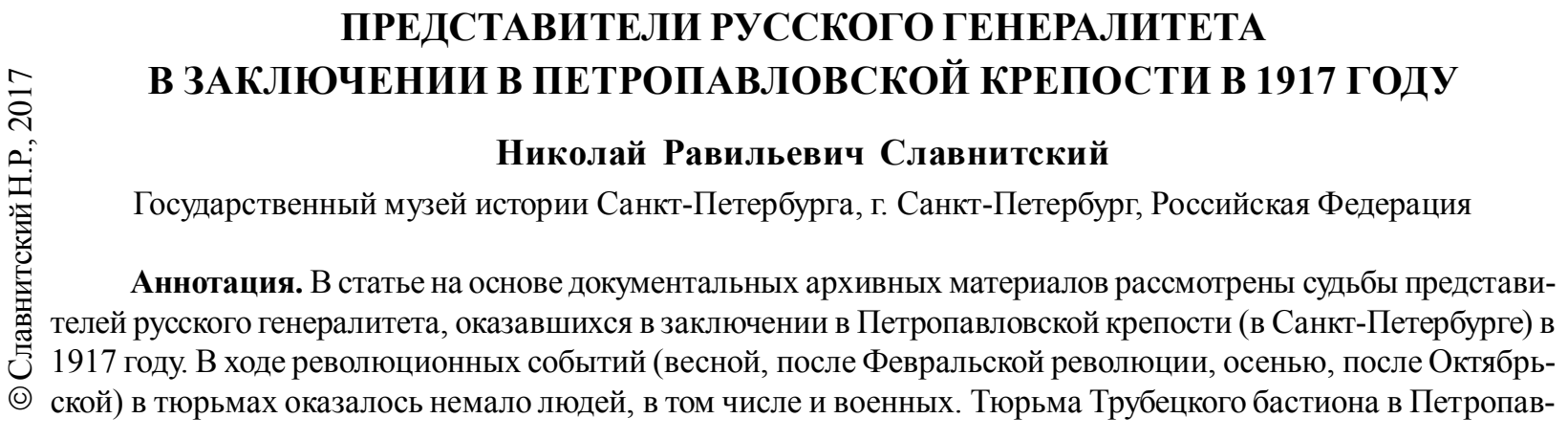


ловской крепости являлась одной из основных политических тюрем, поэтому некоторых генералов отправляли именно туда. В марте в заключении оказались бывшие военные министры, командующий округом, а также те, кто был связан с императорской фамилией. Летом был арестован один из участников выступления Л.Г. Корнилова, а также некоторые монархисты. Третья волна прошла осенью, когда были задержаны военные министры Временного правительства, командование Северным фронтом и другие генералы, выступавшие против советской власти. Всего же за 1917 г. в тюремных помещениях крепости побывало 15 или 16 генералов, причем это были люди самых разных убеждений. Кто-то из них в ходе Гражданской войны оказался на стороне красных, кто-то - на стороне белых, некоторые из них эмигрировали. Поэтому выскажем предположение, что пребывание в заключении в крепости никак не повлияло на их дальнейший выбор. Изучение документальных материалов комендантского управления Петропавловской крепости позволило установить имена тех, кто оказался в ней в заключении, а также выяснить некоторые подробности их заключения.

Ключевые слова: Февральская революция, Октябрьская революция, Петропавловская крепость, политические репрессии, тюрьма Трубецкого бастиона, Гражданская война.

Цитирование. Славнитский Н. Р. Представители российского генералитета в заключении в Петропавловской крепости в 1917 году // Вестник Волгоградского государственного университета. Серия 4, История. Регионоведение. Международные отношения. - 2017. - Т. 22, № 6. - С. 69-76. - DOI: https://doi.org/10.15688/ jvolsu4.2017.6.7

Статья посвящена судьбам представителей русского генералитета в 1917 г., который оказался переломным для каждого из них. Некоторые генералы в ходе революционных событий были арестованы и оказались в заключении в Петропавловской крепости.

Петропавловская крепость в Санкт-Петербурге (Петрограде) еще в XVIII столетии получила неофициальное название «Русская Бастилия», так как постоянно являлась местом заключения политических узников. В то же время в ней регулярно оказывались и офицеры, приговоренные к тюремному заключению за воинские преступления. 1917 год с этой точки зрения оказался особым - среди заключенных крепости на протяжении всего года оказывались генералы российской армии. Данная статья является попыткой посмотреть на революционные события сквозь призму их судеб. В отечественной историографии данный вопрос практически не затрагивался, можно отметить работы А.В. Ганина $[2 ; 3 ; 4]$, подробно рассматривающего биографии выпускников Академии Генерального штаба, но о пребывании генералов в заключении в литературе лишь упоминается. Между тем рассмотрение тех трагических и, возможно, переломных эпизодов их биографий по-прежнему остается актуальным.

Основной источниковой базой статьи являются документальные материалы фонда комендантского управления Петропавловской крепости, хранящиеся в Российском государ- ственном историческом архиве, а также мемуары В.А. Сухомлинова, В.И. Гурко и других заключенных крепости в то время. К сожалению, до нашего времени сохранился не весь массив документов. Скорее всего, делопроизводство вообще велось без какой-либо системы, о сохранности материалов заботились не слишком тщательно, и то, что сохранилось, производит впечатление хаотически собранных бумаг. Тем не менее эти материалы позволяют установить, кто и в какие месяцы оказался в заключении и в каких условиях они там находились. Мемуарные источники дополняют картину, и, кроме того, из них известно, как представители генералитета воспринимали перемену своей судьбы.

Отметим также, что тюремных помещений на территории крепости в то время было несколько. Во-первых, тюремное здание в Трубецком бастионе, возведенное в 18701872 гг. по проекту военных инженеров К.П. Андреева и М.А. Пасыпкина. Здание было построено по инициативе коменданта крепости Н.Д. Корсакова, который задумывал ее в качестве военной тюрьмы для офицеров. Такие регулярно отбывали наказание в казематах крепости, для этого приспосабливали помещения то в одной, то в другой куртине, и в конце концов решили сделать специальное здание. В соответствии с разработанной инструкцией заключенные в эту тюрьму должны были доставляться по распоряжению командующего войсками гвардии и Санкт-Пе- 
тербургского военного округа, и, естественно, тюрьма была исключена из прокурорского надзора. По всей видимости, этим и воспользовалось ІІІ Отделение, добившееся того, чтобы в ней размещали политических заключенных. Уже в феврале 1872 г. она именовалась «зданием для политических арестантов». О каждом узнике, попадавшем сюда, комендант докладывал императору. А для офицеров тюремные помещения продолжали приспосабливать в какой-либо куртине, в основном использовали Екатерининскую куртину (именно там отбывал заключение генерал А.М. Стессель, обвинявшийся в сдаче ПортАртура в период Русско-японской войны).

В 1917 г. практика докладов монарху, естественно, прекратилась, тем не менее документация, связанная с доставлением заключенных в тюрьму Трубецкого бастиона, частично сохранилась. В документах того времени нередко указывалось «Трубецкой бастион», то есть под «бастионом» понималось здание тюрьмы.

В феврале 1917 г. крепость в качестве места заключения практически не использовалась. Бывший германский консул в Эрзеруме Андерс еще 29 января был отправлен в Тифлис [9, л. 3-4]. В это же время в заключении находился рядовой 65-го пехотного Московского полка Адольф Мартынович Карратон, который содержался в крепости с 23 декабря 1916 г., а 25 февраля (то есть уже в ходе революционных событий) он был переведен в Петроградское комендантское управление [14, л. 28]. 27 февраля в тюрьму Трубецкого бастиона были доставлены солдаты лейб-гвардии Павловского полка, отказавшиеся стрелять в демонстрантов, но 28-го числа они были освобождены, и в те же дни было торжественно объявлено, что «Русская Бастилия» пала. Тем не менее вскоре туда стали доставлять бывших министров и государственных деятелей императорской России. Все они официально находились в ведении Чрезвычайной следственной комиссии Временного правительства «для расследования противозаконных по должности бывших министров, главноуправляющих и других высших должностных лиц Российской империи». Среди них были и военные.

Из числа таковых в первую очередь следует отметить В.А. Сухомлинова. Отстранен- ный от должности военный министр оказался в одной из камер тюрьмы Трубецкого бастиона еще в апреле 1916 г. [6, л. 2, 5], а в октябpe того же года был переведен под домашний арест и снова арестован в дни Февральской революции. Причем - по тому же самому делу (по сути, его считали главным виновником того, что страна оказалась не готова к Первой мировой войне, и обвиняли в государственной измене).

В своих воспоминаниях он подробно остановился на обстановке в тюрьме [15, с. 93], и пожалуй, его мемуары являются наиболее подробным описанием тех перемен, которые происходили в 1917 г. в крепости.

Уже 5 марта, то есть спустя несколько дней после прибытия в крепость, В.А. Сухомлинов запросил «цветной карандаш для отметок в следственном деле» [14, л. 15]. Очевидно, что в это время он уже получил следственное дело, то есть по сути работа следователей в отношении него практически не прекращалась.

В те же дни заключенными крепости стали генерал от инфантерии М.А. Беляев (бывший военный министр) и генерал-лейтенант С.C. Хабалов (бывший командующий Петроградским военным округом). Летом они были переведены на Фурштадскую улицу [9, л. 237, 241] (М.А. Беляев - 6 июня, а Хабалов - 20 июля), где находился «арестный дом» и больница при нем. Первый из них, по версии сотрудников НИИ антропологии МГУ, был расстрелян осенью 1918 г. в Петропавловской крепости и похоронен там же (в настоящее время проводится проверка этих данных).

3 марта в Трубецкой бастион был доставлен генерал-майор П.И. Секретев [14, л. 185] - начальник первой военной автомобильной военной школы, который был арестован в связи с тем, что в предыдущие годы был близок к Г.Е. Распутину. В крепости он находился до 31 октября 1917 г;; 9 марта он запросил перо и чернила [14, л. 16].

Обвиняли его в злоупотреблениях в военном ведомстве, что видно из постановления от 16 мая 1917 г.: «1917 г., мая 16 дня производящий следствие по 2-му Отделу Особой следственной комиссии для расследований злоупотреблений по Военному ведомству капитан Броневский предъявил генерал-майору Петру Ива- 
новичу Секретеву обвинение по 142-й 2-й части 145-й статьи Воинского устава о наказаниях и I части 373-й статьи Уложения о наказаниях, согласно постановления от 15 мая сего года и принимая во внимание силу представлявшихся против него улик, строгость угрожающего ему наказания, а равным образом возможность для обвиняемого скрыть следы преступления, руководствуясь 416, 149 и 421 статьями Уголовного Уложения, постановил: избрать мерой пресечения обвиняемому генералмайору Петру Ивановичу Секретову способов уклониться от следствия содержание его под стражей» $[10$, л. 54].

21 октября он был переведен из тюрьмы Трубецкого бастиона на гауптвахту при комендантском управлении крепости [9, л. 305], а освобожден, как уже отмечалось, 31 числа, то есть уже после переворота в Петрограде.

Отметим здесь, что пользоваться письменными принадлежностями в камерах тюрьмы Трубецкого бастиона запрещалось, однако после Февральской революции, судя по всему, про этот пункт инструкции забыли.

Еще одним узником крепости стал генерал от кавалерии П.К. Ренненкампф. Его заключение, по всей видимости, было связано с тем, что в период первой революции весьма жестоко подавил революционные выступления в Восточной Сибири.

14 июля 1917 г. он подал прошение «о допущении в место заключения для собеседования избранного им защитника», однако Чрезвычайная следственная комиссия, рассмотрев это ходатайство, ответила отказом [12, л. 3]. 20 июля он подал прошение об освобождении, но оно было оставлено Чрезвычайной следственной комиссией «без последствий», так как он за ней не числился $[9$, л. 187]. С чем был связан такой ответ, сказать трудно, вполне возможно, что комиссия просто не знала, что с ним делать. К высшим должностным лицам Павел Карлович не относился, но и освободить его комиссия не могла, дабы не будоражить общественное мнение. Поэтому он оставался в крепости до осени 1917 года.

Довольно забавная ситуация сложилась с генералом В.И. Гурко. В августе А.Ф. Керенский прислал на имя коменданта распоряжение о переводе генерала в Екатерининскую куртину, которое сопровождалось разрешени- ем его супруге о «совместном проживании с мужем в месте его заключения» [10, л. 255]. 25 августа он был освобожден по приказанию военного и морского министра с формулировкой «на предмет приведения в исполнение предписания его о высылке Гурко из пределов Российского государства» [10, л. 256]. Однако с высылкой что-то не сложилось, и 30 числа последовало предписание принять его для содержания под стражей в Екатерининской куртине «на прежних основаниях», а 5 сентября он был передан в распоряжение начальника штаба Петроградского военного округа [10, л. 259, 260].

Из мемуаров В.И. Гурко известно, что его действительно намеревались выслать в Англию через Финляндию и Швецию, и он потребовал три дня на сборы, поэтому был освобожден. Вскоре выяснилось, что выезд таким путем невозможен, поэтому было принято решение о новом аресте. И лишь после того, как был согласован новый маршрут (через Архангельск), генерала отправили из крепости за границу (высылка была связана с тем, что он придерживался монархических взглядов) [5, с. 182-184].

8 сентября упоминается генерал-лейтенант, князь А.Н. Долгоруков [9, л. 292], арестованный из-за своего участия в Корниловском мятеже. Доставлен он был 11 августа, освобожден 12 сентября [9, л. 294-295]. Это единственный известный нам военный, оказавшийся в заключении в крепости после подавления выступления Л.Г. Корнилова.

Поле прихода к власти большевиков тюремные помещения продолжали использоваться в такой же мере, как и до этого. Теперь в камерах тюрьмы Трубецкого бастиона оказывались противники советской власти (или люди, заподозренные в этом), и среди них тоже были представители генералитета. Отметим, что с документацией в этот период дело обстояло еще хуже, и большая часть сохранившихся документов касается освобождения заключенных, а вот когда они были задержаны и доставлены в крепость, порой остается не известным.

Первым арестованным генералом стал А.А. Маниковский - управляющий военным министерством, задержанный в Зимнем дворце 25 октября вместе с остальными министра- 
ми Временного правительства. Освобожден он был уже 28 октября 1917 г. [10, л. 7 об.] и в дальнейшем служил в РККА.

В ноябре был выпущен генерал-лейтенант Ф.И. Зубарев [10, л. 33] - начальник Николаевской инженерной академии. Задержан он, по всей видимости, был 25 или 26 числа; с чем был связан арест - не понятно. Вероятнее всего, просто попал под горячую руку во время подавления мятежа юнкеров, что и объясняет быстрое освобождение. Более того, в следующем году Федор Иванович вступил в РККА и возглавил учебную часть Петроградского инженерного техникума.

4 ноября 1917 г. В.А. Антонов-Овсеенко и Н.И. Подвойский распорядились арестовать бывшего главнокомандующего Северным фронтом, генерала от инфантерии В.А. Черемисова и препроводить его в Петропавловскую крепость [11, л. 11]. 14 ноября он был переведен под домашний арест $[10$, л. 84]. Причина его задержания не ясна, можно лишь отметить, что за два дня до ареста В.А. Черемисов доложил о критическом положении вверенных ему войск, отметив, что «если Севфронту не будет оказана продовольственная помощь другими фронтами, то голод наступит через несколько дней». Кроме того, он требовал вывода из полосы фронта 17-го армейского корпуса «по политическим причинам» $[13$, с. 18$]$. Не исключено, что руководство партии большевиков посчитало его неблагонадежным, поэтому и было принято такое решение.

Любопытно, что некоторые руководители белого движения считали, что В.А. Черемисов еще с сентября 1917 г. сотрудничал с большевиками и по этой причине не позволил А.Ф. Керенскому и П.Н. Краснову собрать необходимое количество воинских соединений для подавления восстания в Петрограде в октябре 1917 г. [1, с. 380]. Эта версия, по всей видимости, появилась еще в начале ноября, когда члены «Комитета спасения Революции» (состоявшего по большей части из членов партии эсеров) пытались убедить главнокомандующего Н.Н. Духонина в необходимости замены В.А. Черемисова, считая его единственным препятствием, не позволяющим двинуть на Петроград войска Северного фронта. Н.Н. Духонин даже попытался выз- вать командующего фронтом в Ставку, однако В.А. Черемисов доложил в ответ, что он не может приехать, да и не видит в этом необходимости (кроме того, сообщил, что гарнизон Пскова полностью большевистский и перекрывает любые движения к Петрограду), добавив: «Мое личное влияние на организации, не исключая Революционного комитета, дает некоторую возможность пока предупреждать общий пожар, но я боюсь, что он вспыхнет с моим отъездом, хотя бы рад уехать отсюда совсем, немедленно...» [8, с. 98-99].

1 ноября В.А. Черемисов связывался со своими подчиненными, и один из командармов, В.Г. Болдырев, доложил ему, что часть его армии готова двигаться к Петрограду, но на помощь советскому правительству, и он отговаривает солдат от этого [8, с. 72]. По сути дела, и В.А. Черемисов, и В.Г. Болдырев (тоже вскоре арестованный и оказавшийся в крепости), да и другие командиры в те дни добивались того, чтобы армии Северного фронта занимали нейтральную позицию и не оголили фронт. Вполне вероятно, что такие действия вызвали недовольство не только противников большевиков, но и советских руководителей, поэтому вскоре генералы были арестованы. Хотя в случае с В.А. Черемисовым тюремное заключение оказалось кратковременным.

Заметим, что командование Северного фронта, как минимум, скептически относилось к Временному правительству. Я.Б. Юзефович в разговоре с В.А. Черемисовым заметил: «...сделали все, чтобы лишить возможности командовать, а теперь предъявляют требования; только сознание долга заставляет оставаться на месте, и я завидую рядовому солдату, стоящему в сторожевке» [8, с. 79]. В.А. Черемисов вскоре после освобождения решил эмигрировать и в Гражданской войне не стал принимать участия. Судя по тому, что им в ноябре были недовольны и те, и другие, Владимир Андреевич изначально занимал нейтральную позицию. При этом в разговорах с командующими армиями он подчеркивал, что «мы не имеем права уклоняться от политики и не считаться с политическим настроением массы...» $[13$, c. 161$]$.

В.Г. Болдырев тоже в то время оказался среди заключенных крепости; 19 ноября 
1917 г. упоминается о его переводе из Петропавловской крепости в Выборгскую одиночную тюрьму [11, л. 27]. Его биография очень хорошо известна, арестован он был после того, как отказался признать советскую власть, а освобожден в марте следующего года по амнистии, в дальнейшем боролся с большевиками в составе вооруженных сил эсеров и меньшевиков, хотя после Гражданской войны остался в советской России.

В декабре был освобожден генерал-майop А.В. Бонч-Богдановский [10, л. 99] - командир дивизии в 1917 г., перешедший на службу в РККА в 1918 году. В те же дни упоминается об освобождении генерал-майора И.Ф. Буйвиде [10, л. 108] - тоже командира дивизии. Его судьба сложилась иначе: в 1918 г. он оказался в германской армии, затем (с 1919 г.) в составе Вооруженных сил Юга России (то есть в белом движении). Судьбы упомянутых генералов хорошо иллюстрируют раскол, образовавшийся в среде русского генералитета, - оба были арестованы большевиками практически одновременно и вместе освобождены, а затем их дороги кардинально разошлись.

Генерал-майор А.А. Оноприенко был выпущен немного позднее - 21 декабря 1917 г. $[10$, л. 127] - еще один командир дивизии, позднее оказавшийся в белом движении.

В декабре 1917 и январе 1918 г. среди освобожденных дважды называется генерал Новицкий. 9 декабря есть упоминание о его освобождении [10, л. 113], и аналогичная запись встречается 2 января [10, л. 146]. Имя (или имена) ни в том, ни в другом случае не указаны. Ситуацию запутывает то, что в то время в российской армии было три генерала Новицких - Евгений Федорович (1867-1931), генерал-лейтенант, Василий Федорович (18691929), генерал-майор, и Федор Федорович (1870-1944), тоже генерал-майор [2, с. 294].

Евгений Федорович Новицкий был переведен в резерв чинов Одесского военного округа за болезнью 14 июля 1917 г. [2, с. 426], позже эмигрировал в Югославию [3, с. 107108], его пребывание в Петрограде осенью 1917 г. маловероятно, но все же не исключено.

Василий Федорович Новицкий 16 декабря 1917 г. стал профессором Николаевской военной академии [2, с. 432]. Весной 1917 г. он занимал должность помощника военного министра [4, с. 128], а в ноябре того же года являлся командующим 12-й армии Северного фронта. На этом посту он пытался противостоять процессу разложения армии, что привело к конфликту с военно-революционным комитетом [13, с. 162-163], а затем, по всей видимости, и к кратковременному аресту.

По каким причинам упомянутые выше генералы были арестованы большевиками, к сожалению, установить пока не удалось. В переписке комендантского управления об этом никаких сведений нет (еще раз обратим внимание, что сохранились лишь документы об их освобождении, не известно даже, когда они попали в крепость). Остается предположить, что они просто попали «под горячую руку».

Отметим также, что среди заключенных крепости были и генералы полицейского ведомства - М.С. Комиссаров, Е.К. Климович, А.И. Спиридович [7, л. 13, 45], а также представители высшего командного состава из военно-морского ведомства: вице-адмирал И.Ф. Бострем, контр-адмирал Григоров [10, л. 111, 138].

Упоминавшийся в начале статьи В.А. Сухомлинов оставался заключенным тюрьмы Трубецкого бастиона вплоть до 1 марта 1918 года. В мемуарах он довольно подробно описал, как менялась обстановка в тюрьме в течение 1917 года. Поначалу в бастионе сохранялась прежняя «наблюдательная команда», но вскоре там появились другие подразделения, установившие новые порядки, которые бывший военный министр назвал «бесчеловечными» и «инквизиторскими» [15, c. 292]. Это подтверждается и другими мемуаристами. В.А. Сухомлинов отмечал, что постепенно хозяйство стало приходить в расстройство, белье выдавали рваное и грязное, с питанием тоже обстояло плохо [15, с. 293]. Изменилась ситуация лишь ближе к лету, когда к заключенным был допущен доктор И.И. Манухин, много сделавший для облегчения их участи (и добившийся того, что большинство узников были переведены в другие тюрьмы или освобождены).

После прихода к власти большевиков, по его же словам, режим для заключенных был значительно смягчен, но в то же время у многих из них появились опасения за свои 
жизни $[15$, с. 320$]$. В то время улучшилось питание (правда, лишь благодаря усилиям политического «Красного креста», что отмечал в своем дневнике также А.И. Шингарев [16, c. 49]), были разрешены прогулки не поодиночке (как раньше), а всем заключенным вместе, благодаря чему они знали, кто находится в камерах $[15$, с. 320]. Здесь отметим любопытный момент: мемуарист перечислил многих из своих «товарищей по несчастью», однако никаких упоминаний о других генералах (которых он должен был знать) у него не имеется.

Караульная команда, по данным мемуаристов, с марта 1917 г. вплоть до конца года не менялась, хотя большевики после прихода к власти старались заменить ее матросами Балтийского флотского экипажа. При этом, по словам А.И. Шингарева, надзиратели вели себя корректно по отношению к узникам [16, с. 21]. То есть те же самые люди, которые весной выглядели «инквизиторами», к осени стали лучше относиться к заключенным. Здесь, конечно, необходимо учитывать, что это писал один из лидеров партии кадетов и министр Временного правительства, то есть человек, к которому участники Февральской революции относились хорошо, но и В.А. Сухомлинов отмечал, что стража стала вести себя спокойнее после октябрьских событий.

Подводя итоги, отметим, что за 1917 г. в тюремных помещениях крепости побывало 15 или 16 генералов, причем это были люди самых разных убеждений. Это было связано и с тем, что в стране менялись правительства, в результате чего сначала в заключении оказались те, кто являлся монархистом (или был заподозрен в этом), а осенью люди, служившие также и при Временном правительстве. При этом для всех партий, оказывавшихся у власти в течение 1917 г., генералы были «чужеродным элементом», поэтому многие представители генералитета оказывались в заключении.

Кто-то из них в ходе Гражданской войны оказался на стороне красных, кто-то - на стороне белых, некоторые из них эмигрировали. Поэтому выскажем предположение, что пребывание в заключении в крепости никак не повлияло на их дальнейший выбор.

\section{СПИСОК ЛИТЕРАТУРЫ}

1. Врангель, П. Н. Записки / П. Н. Врангель. Т. 1. - Минск : Харвест, 2002. -478 с.

2. Ганин, А. В. Корпус офицеров Генерального штаба в годы Гражданской войны, 1917-1922. Справочные материалы / А. В. Ганин. - М. : Русский путь, 2009. - 894 с.

3. Ганин, А. В. Общество русских офицеров Генерального штаба в Королевстве сербов, хорватов и словенцев / А. В. Ганин // Руска дијаспора и словенски свет. Зборник радова (Русское зарубежье и славянский мир : сб. тр.). - Београд : Славистичко друштво Србије, 2013. - С. 107-116.

4. Ганин, А. В. Как становятся антибольшевиками? Генерал Е.К. Миллер и революционная армия в 1917 году / А. В. Ганин // Первая мировая война и Европейский Север России. - Архангельск : Сев. (Аркт.) федер. ун-т им. М.В. Ломоносова, 2014. - С. 121-132.

5. Гурко, В. И. Война и революция в России / В. И. Гурко. - М. : Центрполиграф, 2007. - 399 с.

6. Дело о генерале Сухомлинове // Российский государственный исторический архив (РГИА). Ф. 1280. - Оп. 1. - Д. 1116.

7. О заключении политических арестованных в Петропавловскую крепость // РГИА. - Ф. 1280. Оп. 1. -Д. 1114.

8. Октябрь на фронте // Красный архив. 1927. - № 5. - С. 71-107.

9. О медицинском освидетельствовании политических арестованных//РГИА.-Ф. 1280.-Оп. 1.-Д. 1113.

10. Ордера об освобождении и переводе в другие тюрьмы // РГИА. - Ф. 1280. - Оп. 1. - Д. 1112.

11. Ордера о содержании и копии постановлений о содержании // РГИА. - Ф. 1280. - Оп. 1. - Д. 1377.

12. Пропуска для свидания с арестованными, выданные Военно-революционным комитетом // РГИА. -Ф. 1280. - Оп. 1. - Д. 1371.

13. Разложение армии в 1917 году / подгот. к печати Н. Е. Какуриным. - М. ; Л. : Гос. соц.-экон. изд-во, 1925. - 190 с.

14. Разная переписка входящих бумаг // РГИА. Ф. 1280. -Оп. 1.-Д. 1110.

15. Сухомлинов, В. А. Воспоминания В.А. Сухомлинова / В. А. Сухомлинов. - М. ; Л. : Гос. изд-во, 1926. $-334 \mathrm{c}$.

16. Шингарев, А. И. Как это было. Дневник А.И. Шингарева. Петропавлоская крепость, 27.XI.17 -5.I.18 / А. И. Шингарев. - М. : Комиссия по увековечиванию памяти Ф.Ф. Кокошкина и А.И. Шингарева, 1918. -68 с.

\section{REFERENCES}

1. Vrangel P.N. Zapiski [Memoirs]. Minsk, Kharvest Publ., 2002, vol. 1. 478 p. 
2. Ganin A.V. Korpus ofitserov Generalnogo shtaba v gody Grazhdanskoy voyny, 1917-1922. Spravochnye materialy [The Corps of Officers of the General Staff during the Civil War, 1917-1922. Reference Materials]. Moscow, Russkiy put Publ., 2009. 894 p.

3. Ganin A.V. Obshchestvo russkikh ofitserov Generalnogo shtaba v Korolevstve serbov, khorvatov i sloventsev [The Society of Russian Officers of the General Staff in the Kingdom of Serbs, Croats and Slovenes]. Ruska dijaspora i slovenski svet. Zbornik radova (Russkoe zarubezhye i slavyanskiy mir: sb. tr.). Beograd, 2013, pp. 107-116.

4. Ganin A.V. Kak stanovyatsya antibolshevikami? General E.K. Miller i revolyutsionnaya armiya v 1917 godu [How to Become Anti-Bolsheviks? General E.K. Miller and the Revolutionary Army in 1917]. Pervaya mirovaya voyna i Evropeyskiy Sever Rossii [The First World War and the European North of Russia]. Arkhangelsk, 2014, pp. 121-132.

5. Gurko V.I. Voyna i revolyutsiya v Rossii [War and Revolution in Russia]. Moscow, Tsentrpoligraf Publ., 2007. 399 p.

6. Delo o generale Sukhomlinove [The Case of General Sukhomlinov]. Rossiyskiy gosudarstvennyy istoricheskiy arkhiv [Russian State Historical Archive], F. 1280, Op. 1, D. 1116.

7. O zaklyuchenii politicheskikh arestovannykh v Petropavlovskuyu krepost [On the Conclusion of Political Prisoners in the Peter and Paul Fortress]. Rossiyskiy gosudarstvennyy istoricheskiy arkhiv [Russian State Historical Archive], F. 1280, Op. 1, D. 1114.

8. Oktyabr na fronte [October at the Front]. Krasnyy arkhiv, 1927, no. 5, pp. 71-107.

9. O meditsinskom osvidetelstvovanii politicheskikh arestovannykh [About Medical
Examination of Political Prisoners]. Rossiyskiy gosudarstvennyy istoricheskiy arkhiv [Russian State Historical Archive], F. 1280, Op. 1, D. 1113.

10. Ordera ob osvobozhdenii i perevode v drugie tyurmy [Orders for Release and Transfer to Other Prisons]. Rossiyskiy gosudarstvennyy istoricheskiy arkhiv [Russian State Historical Archive], F. 1280, Op. 1, D. 1112.

11. Ordera o soderzhanii i kopii postanovleniy o soderzhanii [Orders for the Content and Copies of Resolutions on the Content]. Rossiyskiy gosudarstvennyy istoricheskiy arkhiv [Russian State Historical Archive], F. 1280, Op. 1, D. 1377.

12. Propuska dlya svidaniya s arestovannymi, vydannye Voenno-revolyutsionnym komitetom [Passes for Visits to Arrested Persons, Issued by the Military Revolutionary Committee]. Rossiyskiy gosudarstvennyy istoricheskiy arkhiv [Russian State Historical Archive], F. 1280, Op. 1, D. 1371.

13. Kakurin N.E., ed. Razlozhenie armii v 1917 godu [Degradation of the Army in 1917]. Moscow; Leningrad, Gos. sots.-ekon. izd-vo, 1925. 190 p.

14. Raznaya perepiska vkhodyashchikh bumag [Different Correspondence of Incoming Papers]. Rossiyskiy gosudarstvennyy istoricheskiy arkhiv [Russian State Historical Archive], F. 1280, Op. 1, D. 1110 .

15. Sukhomlinov V.A. Vospominaniya V.A. Sukhomlinova [Memories of V.A. Sukhomlinov]. Moscow; Leningrad, Gos. izd-vo, 1926. 334 p.

16. Shingarev A.I. Kak eto bylo. Dnevnik A.I. Shingareva. Petropavloskaya krepost, 27.XI.17 5.I.18 [How It Was. Diary of A.I. Shingarev. Peter and Paul Fortress, 27.XI.17 - 5.I.18.]. Moscow, Komissiya po uvekovechivaniyu pamyati F.F. Kokoshkina i A.I. Shingareva, 1918. $68 \mathrm{p}$.

\section{Information about the Author}

Nikolay R. Slavnitskiy, Candidate of Sciences (History), Chief Researcher, State Museum of the History of St. Petersburg, Peter and Paul Fortress, 3, 197046 Saint Petersburg, Russian Federation, slavnitski@bk.ru, https://orcid.org/0000-0002-1590-9423

\section{Информация об авторе}

Николай Равильевич Славнитский, кандидат исторических наук, главный научный сотрудник, Государственный музей истории Санкт-Петербурга, Петропавловская крепость, 3, 197046 г. Санкт-Петербург, Российская Федерация, slavnitski@bk.ru, https://orcid.org/0000-0002-1590-9423 